\title{
The adverse influence of spina bifida occulta on the medical treatment outcome of primary monosymptomatic nocturnal enuresis
}

\author{
Basri Cakiroglu ${ }^{1}$, Tuncay Tas ${ }^{2}$, Seyit Erkan Eyyupoglu ${ }^{3}$, Aydın İsmet Hazar ${ }^{2}$, \\ Mustafa Bahadır Can Balcı ${ }^{2}$, Yunus Nas ${ }^{4}$, Fazli Yilmazer ${ }^{4}$, Suleyman Hilmi Aksoy ${ }^{5}$ \\ ${ }^{1}$ Hisar Intercontinental Hospital, Department of Urology, Umraniye, Istanbul, Turkey; \\ ${ }^{2}$ Taksim Training and Research Hospital, Department of Urology, Taksim, Istanbul, Turkey; \\ ${ }^{3}$ Amasya Training and Research Hospital, Department of Urology, Amasya, Turkey; \\ ${ }^{4}$ Hisar Intercontinental Hospital, Department of Pediatry, Umraniye, Istanbul; \\ ${ }^{5}$ Hisar Intercontinental Hospital, Department of Radiology, Umraniye, Istanbul, Turkey.
}

\begin{abstract}
Summary Objective: Previous reports have suggested that the incidence of spina bifida occulta $(\mathrm{SBO})$ in patients with primary monosymptomatic nocturnal enuresis (PMNE) is higher than the general population. The purpose of this study was to investigate the effect of spina bifida occulta on the medical treatment outcome of PMNE.

Material and Methods: Between January 2008 and December 2011, a total of 223 children (151 boys and 72 girls, aged 6-16 years; mean age: $10.1 \pm 3.04$ years) with PMNE were reviewed retrospectively. All of the children underwent physical examination, urine analysis, urinary tract ultrasonography and kidney ureter bladder (KUB) scout film. All patients were initially treated with a timed voiding program and were given desmopressin acetate when necessary.

Results: Spina bifida occulta was detected in 75 children (33.6\%). Spina bifida occulta affected L4 in 2 children, L5 in 6 children, L4-L5 in 3 children, S1 in 52 children, S2 in 7 children and S1-S2 in 2 children. Treatment was successful in $79 \%$ of the children without SBO, and in only $48 \%$ of the children with SBO. Medical treatment success rates differed significantly between the study groups. Conclusion: The presence of spina bifida occulta significantly affects the response to medical treatment in patients with PMNE. Thus, verifying spina bifida occulta status in PMNE can facilitate prognostic predictions about the response to medical treatment.
\end{abstract}

KEY WORDS: Spina bifida occulta; Primary monosymptomatic nocturnal enuresis; Children; Desmopressin.

Submitted 15 June 2014; Accepted 14 July 2014

\section{INTRODUCTION}

Enuresis nocturna is a common health problem among children and adolescents. While the prevalence of enuresis at the age of 5 is as high as $15-20 \%$, the prevalence decreases to $1-2 \%$ above 17 years of age. The spontaneous recovery rate in enuretic patients has been estimated to be $15 \% / y e a r(1)$. Although many factors have been suggested to play a role in the etiology of enuresis including nocturnal polyuria, sleep disturbances, reduced bladder capacity, detrusor instability and urinary tract infections, the exact cause is still unclear $(2,3)$. In the absence of any additional lower urinary tract symptoms of, including urgency or daytime incontinence enuresis is defined as mono-symptomatic nocturnal enuresis (MNE) (4). Treatment gains more importance in order to improve self-esteem and life standard of these children. Nowadays, a variety of treatment modalities have been used for the treatment of enuresis nocturna including desmopressin, tricyclic antidepressants and behavioral therapy. However, the reason why some enuretic children respond poorly to medical treatment is not clearly elucidated.

Spina bifida (SB) is a congenital deformity involving failure of normal midline fusion of the neural tube. The exact etiology of SB is still unknown, but there is growing evidence in favor of a multifactorial origin. The term includes both spina bifida occulta (SBO), which involves only a bony (vertebral) arch defect and spina bifida (SB) cystica (aperta), which involves a bony defect and a neural tube (spinal cord) defect (5). In SBO, there's a small defect or gap in one or more vertebrae. The commonest type is $\mathrm{SBO}$, in which there is a defect in the vertebral arch of L5 or S1, resulting in the failure of posterior arch to fuse in the midline. Many authors have published data on the frequency of $\mathrm{SBO}$, with varying results. In fact, it's been estimated that $12-23 \%$ of healthy people have SBO $(6,7)$.

Interestingly it has been reported earlier that; among patients with enuresis, the incidence of $\mathrm{SBO}$ has been increased up to $37.5 \%$ (8). However, the effect of SBO on the response to nocturnal enuresis (NE) treatment is controversial. In this study, we aimed to investigate the association between the presence of SBO and medical treatment outcome in patients with primary monosymptomatic MNE. 


\section{MATERIAL AND METHODS}

A total of 223 children, aged 6-16 years, who have been diagnosed with PMNE in the urology outpatient clinic of Hisar Intercontinental Hospital between January 2008 and December 2011, were enrolled to the study. The study protocol was approved by the ethical committee, of Taksim Training and Research Hospital (Ethical Code: Taksim Training and Research Hospital, Etics Committee of Clinical Research No.31/04.12.2013)

The diagnosis of MNE was in accordance with the International Children's Continence Society standardization (4). Children with a minimum of one wet night per week were included in the study. All patients underwent a detailed clinical evaluation including; medical history, physical examination, urinalysis, urinary tract ultrasonography, and kidney-ureter-bladder scout film. Plain radiography of the spine had been performed to all patients before the start of treatment Patients with a history of urinary tract infection or neurological disease and dysfunctional elimination syndrome (children who have problems with both bowel and bladder control with chronic constipation, fecal retention, stool withholding and encopresis). Written informed consents were obtained from the parents of the patients.

On plain X-ray films of the spine, the presence or absence of the fusion of the posterior elements of the lumbar and/or sacral spinous processes were examined to in order to detect SBO. X ray films were evaluated by experienced radiologists and, the initial SBO diagnosis was confirmed with subsequent computed tomography imaging.

The children were assigned to one of the 2 treatment groups according to the treatment they receive; either desmopressin monotheraphy or combination therapy including tolteradine with desmopressin

Patients were homogenously assigned to treatment groups with regard to the presence or absence of SBO. The children and parents had underwent thorough counseling which involved a review of the usual interval between dinner and bedtime (aiming to prolong that period to over 3 hours), a review of the hydration state of each child (aiming to restrain night-time hydration), and a discussion of the treatment plan and its goals. In the single drug therapy group, the initial daily doses were $0.2 \mathrm{mg}$ for desmopressin. In the desmopressin only group dosage had been adjusted by increments of $0.2 \mathrm{mg}$ at 2 weeks in case of insufficient response and the maximal dosage for desmopressin was $0.4 \mathrm{mg}$ at bedtime. The drug was administered orally 30 minutes before bedtime. Patients had been asked to record whether they were "wet" or "dry" the next morning. "Wet" and "dry" nights were documented daily for 14 days before treatment (baseline) and during the 6-month treatment period.

We calculated the baseline enuretic frequency from the data collected prior to medical treatment commencement. We also calculated the frequency of enuresis from the data collected at 1, 3 and 6 months after the initiation of medical treatment. Efficacy was measured based on the percentages of 5 patient responses. Response was categorized as "excellent" when the frequency of NE decreased to zero or to once monthly, "good" when frequency decreased by more than $90 \%$ compared to base- line, "fair" when frequency decreased by more than 70\%, "partial" when frequency decreased by $50 \%$ or more and "no response" when frequency decreased by less than $50 \%$. The final follow-up visit was performed at 6 months after the start of treatment. Complete and good response was considered as successful treatment.

\section{Statistical analyses}

All analyses were performed using SPSS 11.5 (Statistical Package for Social Sciences, Chicago, USA). Data were expressed as mean values \pm standard deviation. ChiSquare analysis was used to examine the significance of response to treatment between the 2 groups. A value of $\mathrm{p}<0.05$ was considered as statistically significant.

\section{RESULTS}

Charts of a total of 223 children (151 boys and 72 girls, aged $6-16$ years; mean age: $10.1 \pm 3.04$ years who have been diagnosed with PMNE were reviewed retrospectively. Spina bifida occulta was detected in 75 children (33.6\%). SBO affected L4 in 2 children, L5 in 6 children, L4-L5 in 3 children, and S1 in 52 children, S2 in 7 children and S1-S2 in 2 children (Table 2).

Response to treatment among patients with and without SBO is summarized in Table 3.

Treatment was successful in $79 \%$ of the children without SBO, and in only $48 \%$ of the children with SBO. The difference between those with and without SBO was statistically significant in terms of the medical treatment success rate $(p<0.001)$.

Table 1.

Demographical features of the study groups.

\begin{tabular}{|c|c|c|c|c|}
\hline & \multicolumn{4}{|c|}{ Response to treatment } \\
\hline & $M / F$ & Age (years) & $\mathbf{N}$ & $\%$ \\
\hline $\begin{array}{l}\text { Nocturnal enuresis without spina bifida } \\
\text { Group I }(n=148)\end{array}$ & $92 / 56$ & $9.6 \pm 2.9$ & 117 & 79* \\
\hline $\begin{array}{l}\text { Nocturnal enuresis with spina bifida } \\
\text { Group II }(n=75)\end{array}$ & $59 / 16$ & $11.1 \pm 3.0$ & 36 & 48 \\
\hline
\end{tabular}

Table 2.

Incidence and distribution of spina bifida occulta in the study population.

\begin{tabular}{|l|c|c|c|}
\hline L4 & Male & Female & Total \\
\hline $\mathbf{L 5}$ & 1 & 1 & 2 \\
\hline $\mathbf{L 4 - 5}$ & 5 & 1 & 6 \\
\hline $\mathbf{L 5 - S 1}$ & 1 & 2 & 3 \\
\hline $\mathbf{S 1}$ & - & 3 & 3 \\
\hline $\mathbf{S 2}$ & 5 & 47 & 52 \\
\hline S1-S2 & 3 & 4 & 7 \\
\hline & 1 & 1 & 2 \\
\hline
\end{tabular}


Table 3.

Treatment outcomes in the study groups.

\begin{tabular}{|l|c|c|}
\hline Treatment outcome & $\begin{array}{c}\text { EN patients with SBO } \\
\text { (n= 75) }\end{array}$ & $\begin{array}{c}\text { EN patients without SBO } \\
(\mathbf{n}=\mathbf{1 4 8 )}\end{array}$ \\
\hline Complete response & $30(40,0 \%)$ & $106(71,6 \%)$ \\
\hline Good response & $6(8,0 \%)$ & $11(7,4 \%)$ \\
\hline Partial response & $26(34,7 \%)$ & $12(8,1 \%)$ \\
\hline No response & $13(17,3 \%)$ & $19(12,8 \%)$ \\
\hline EN: Enuresis nocturna, SBO: Spina bifida occulta.
\end{tabular}

\section{Discussion}

Spina bifida occulta $(\mathrm{SBO})$ is a variable syndrome with manifestations such as vertebral cleft, foot deformities, midline skin lesions, spondylolysis, syringomyelia, tethered cord syndrome and genitourinary dysfunction. Enuresis may be the only evidence of the disease (9).

The data concerning the effect of $\mathrm{SBO}$ in treatment response among patients with enuresis nocturna is controversial. In a recent study, similar to our findings, Shin et al. studied 160 children with enuresis and reported a higher success rate with desmopressin response rate in the group without $\mathrm{SBO}$ compared to the group with $\mathrm{SBO}$ (10). In another study conducted by Miyazato et al., although there was no difference in the overall response rates between children with and without $\mathrm{SBO}$, patients with $\mathrm{L}$ and L/S SBO were less responsive to treatment compared to the patients with S SBO (11). On the other hand Kumar et al., reported that outcome of patients with SBO was not different than the patients without $\mathrm{SBO}$. However, they only compared the outcome of patients on behavioral therapy (12). In an earlier study, Ritchew et al. compared the treatment success rates among 127 children with diurnal enuresis. Among those, 48 patients were having SBO and all 127 patients were initially treated with a timed voiding program and 28 with persistent enuresis were given anticholinergic medications. The mean follow-up for both groups was 3 years and the authors determined that the outcome for enuretic children with SBO was comparable to those with normal spine x-rays (13). In their prospective study, Kajbafzadeh et al. evaluated 109 children with less than $50 \%$ reduction in wet nights despite different treatments for at least 6 months. They specifically looked for the presence of associated SBO and compared the treatment outcome with the outcomes of 40 healthy children. They determined that SBO was present in $86(78,9 \%)$ patients with persistent primary NE and 10 (25\%) normal children and the difference was statistically significant (14). Despite the fact that, this was a cross-sectional study and a direct causal relationship could not be made with these findings, this data also supports that there may be a common developmental etiology between unresponsive enuretic patients and $\mathrm{SBO}$.

This finding is also imperative to realize the increased rates of medical treatment unresponsiveness among patients with enuresis nocturna.

In normal healthy children the incidence of $\mathrm{SBO}$ is about $17-23 \%$ while SBO incidence reaches $35-60 \%$ in enuret- ic children (15-17). Although the exact mechanism linking these two pathologies is not obvious, everyone should be aware of this association since these two conditions, are common in childhood. Moreover recent increase in the prevalence of SBO may also result in an increased prevalence of NE because of this association. $\mathrm{SBO}$ of the sacrum is the most common type of spinal deformity. Spina bifida cystica and occulta present with a wide spectrum of urodynamic abnormalities including upper and lower motor neuron types of bladder and urethral dysfunction (18). It has been suggested that SBO might be associated with incomplete neurogenesis of the sympathetic nerves that control the internal sphincter at the vesicourethral junction. These dysfunctions may be the cause of association of $\mathrm{SBO}$ and enuresis nocturna but studies are warranted to determine the exact link between these disorders (10). In another interesting study dealing with this subject, Dik et al. studied 241 patients with SB and determined that 13 of them had true NE. These patients were treated with desmopressin $(0,4 \mathrm{mg}, 1 \mathrm{x} 1)$ and the drug was successful in 12 patients: only 1 of whom relapsed during the follow-up follow up (19). This study is also important in terms of that; response rate was very high despite the presence of SBO. However since the number of patients was as low as 13 , strict conclusions can not be drawn with this data. In our study with 223 subjects with PMNE, we have determined that children with SBO have poorer medical treatment response at 6 months than those without this deformity.

Enuresis nocturna is an important health problem, distressing social lives of all affected children and their families. Although many treatment modalities are present; it is still not clear why some children do not respond to medical treatment while some of them recover spontaneously. In that aspect, it may be helpful for the physicians to determine associated conditions that may play a role in predicting medical treatment success rate in enuresis nocturna.

\section{Conclusion}

The presence of SBO affects the response to medical treatment among patients with primary MNE. If the increasing prevalence of SBO is considered, this phenomenon gains more importance. In the light of these data, we suggest that determination of the existence of SBO may be helpful to predict the response to treatment in PMNE. Future prospective, randomized studies comparing the efficacy of different treatment modalities with regard to the presence of absence of SBO are warranted in order to assess SBO's real prognostic value in this setting.

\section{REFERENCES}

1. Alon U. Nocturnal enuresis. Pediatr Nephrol. 1995; 9:94-103.

2. Ozden C, Ozdal OL, Altinova S, et al. Prevalence and associated factors of enuresis in Turkish children. Int Braz J Urol. 2007; $33: 216-22$

3. Pereira RF, Silvares EF, Braga PF. Behavioral alarm treatment for nocturnal enuresis. Int Braz J Urol. 2010; 36:332-8. 
4. Neveus T, von Gontard A, Hoebeke P, et al. The standardization of terminology of lower urinary tract function in children and adolescents; report from the standardization committee of the International Children's Continence Society. J Urol. 176:314-324.

5. De Marco P, Merello E, Mascelli S, et al. Current perspectives on the genetic causes of neural tube defects. Neurogenetics.. 2006; 7:201-21.

6. Eubanks JD, Cheruvu VK. Prevalence of sacral spina bifida occulta and its relationship to age, sex, race, and the sacral table angle: an anatomic, osteologic study of three thousand one hundred specimens. Spine (Phila Pa 1976). 2009; 34:1539-43.

7. Fidas A, MacDonald HL, Elton RA, et al. Prevalence and patterns of spina bifida occulta in 2707 normal adults. Clin Radiol. 1987; 38:537-42.

8. Agarwal HC, Mohan D, Mukerji DP. Eneuresis. An etiological and therapeutic review. Indian J Med Sci. 1967; 21:668-75.

9. Zambito A, Dall'oca C, Polo A, et al. Spina bifida occulta. Foot deformities, enuresis and vertebral cleft: clinical picture and neurophysiological assessment. Eur J Phys Rehabil Med. 2008; 44:437-40

10. Shin SH, Im YJ, Lee M-J, et al. Spina bifida occulta: not to be overlooked in children with nocturnal enuresis. Int J Urol. 2013; 20:831-5.

11. Miyazato M, Sugaya K, Nishijima S, et al. Location of spina bifida occulta and ultrasonographic bladder abnormalities predict the outcome of treatment for primary nocturnal enuresis in children. Int J Urol. 2007; 14:33-38.

12. Kumar P, Aneja S, Kumar R, et al. Spina bifida occulta in functional enuresis.. Indian J Pediatr. 2005; 72:223-5.

13. Ritchey ML, Sinha A, Di Pietro MA, et al. Significance of spina bifida occulta in children with diurnal enuresis. J Urol. 1994; 152:815-8.

14. Kajbafzadeh A, Espandar L, Mehdizadeh M, et al. Spina bifida occulta in persistent primary nocturnal enuresis. Iran J Radiol. 2004; 66 .

15. Kawauchi A, Kitamori T, Imada N, et al. Urological abnormalities in 1,328 patients with nocturnal enuresis. Eur. Urol. 1996; 29:231-4.

16. Samuel M, Boddy SA. Is spina bifida occulta associated with lower urinary tract dysfunction in children? J Urol. 2004; 171:2664-6.

17. Boone D, Parsons D, Lachmann SM, et al. Spina bifida occulta: lesion or anomaly? Clin. Radiol. 1985; 36:159-61.

18. Sakakibara R, Hattori T, Uchiyama T, et al. Uroneurological assessment of spina bifida cystica and occulta. Neurourol. Urodyn. 2003; 22:328-34.

19. Dik P, Veenboer PW, and de Jong T. Desmopressin in the treatment of nocturnal enuresis in patients with spina bifida. Cerebrospinal Fluid Research 2010; 7(Suppl 1):S10.

\section{Correspondence}

Basri Cakıroglu, MD, Urologist (Corresponding Author)

drbasri@gmail.com

Hisar Intercontinental Hospital, Department of Urology

Saray Mah. Siteyolu Cad.No:7, 34768 Umraniye, Istanbul, Turkey

Tuncay Tas, MD, Urologist

drtastuncay@gmail.com

Aydın İsmet Hazar, MD, Urologist

mdhazar@yahoo.com

Mustafa Bahadir Can Balcl, MD, Urologist

drbalci@yahoo.com

Taksim Training and Research Hospital, Department of Urology

Taksim, Istanbul, Turkey

Seyit Erkan Eyyupoglu, MD, Urologist

seeseesee@hotmail.com

Amasya Training and Research Hospital, Department of Urology

Amasya, Turkey

Yunus Nas, MD, Pediatrist

ynas@hisarhospital.com

Fazli Yilmazer, MD, Pediatrist

fyilmazer@hisarhospital.com

Hisar Intercontinental Hospital, Department of Pediatry

Umraniye,Istanbul

Suleyman Hilmi Aksoy, MD, Radiologist

saksoy@hisarhospital.com

Hisar Intercontinental Hospital, Department of Radiology

Umraniye, Istanbul, Turkey 